\title{
Effectiveness of Multimedia Education Program on the Development of Self-Help and Life Skills in Educable, crossurn Mentally Retarded Students
}

\author{
Faranak Mosavi $^{1 *}$, Zeynab Abazari ${ }^{1}$, Faramarz Beigipoor $^{1}$, Nasrin Asadi $^{2}$
}

1. Department of Educational Management, Faculty of Humanities, Kermanshah Branch, Islamic Azad University, Kermanshah, Iran

2. Department of Occupational Therapy, University of Social Welfare and Rehabilitation Sciences, Tehran, Iran.

Citation: Mosavi F, Abazari Z, Beigipoor F, Asadi N. Effectiveness of Multimedia Education Program on the Development of Self-Help and Life Skills in Educable, Mentally Retarded Students. Iranian Rehabilitation Journal. 2016; 14(3):179-184. https://doi.org/10.18869/nrip.irj.14.3.179

: https://doi.org/10.18869/nrip.irj.14.3.179

\section{Article info:}

Received: 03 Feb. 2016

Accepted: 17 Jun. 2016

\section{Keywords:}

Multimedia education, Life skills, Self-help, Students with intellectual disability

\section{A B STRACT}

Objectives: Multimedia messages are designed considering how the human brain functions as opposed to other forms of media that are not planned accordingly. They are likely to lead to more effective and meaningful learning. In the cognitive theory of multimedia learning, it is assumed, firstly, that the human information processing system has two separate channels for processing: visual and auditory.

Methods: This research is an applied one in terms of objective. A pretest and posttest, with a control group, research design for the collection of data also makes it a quasi-experimental one. The statistical population included all educable, mentally retarded students in grades two and three of elementary schools in Qasr-e Shirin in the academic year 2014-2015. Twelve students were selected through accessible sampling method and were randomly assigned into control and experimental groups.

Results: The results showed that the implementation of multimedia training is effective in the development of self-help and life skills of educable, mentally retarded students.

Discussion: The findings indicated that multimedia education can be used to develop self-help and life skills along with traditional methods.

\section{Introduction}

A

ccording to statistics, between 1.5-2.5 percent of the country's children are mentally retarded [5]. Shortcomings and limitations in adaptive and social skills are the defining features of mental retardation, and this point well has been confirmed in studies. Studies show that $13-75$ percent of mentally retarded children are af- flicted with adaptive and social disorders [3] Several studies have also shown that lack of self-help and life skills' training among mentally retarded students worsen learning difficulties, has a negative impact on academic performance and prevents students' academic progress.

The researcher's study in the field of education of mentally retarded children led him to conclude that these children, due to their low attention span and significant

* Corresponding Author:

Faranak Mosavi, PhD

Address: Department of Educational Management, Kermanshah Branch, Islamic Azad University, Kermanshah, Iran.

Tel: +98 (918) 3311176

E-mail:frnkmosavi@yahoo.com 
weakness of motivation, learn much less, do not retain their learning and sometimes state what they have learned incorrectly. Traditional and non-active teaching methods that require abstract thinking is tedious and boring for them. The students would enjoy learning if a varied and interesting curriculum were to be interspersed with videos. Given that self-help and life skills' training is important for students with special needs and appropriate multimedia applications have not been designed to cater to this need, the researchers decided to evaluate its effect on the development of the said skills among educable, mentally retarded students in grades two and three of elementary schools.

Education offered through the prism of multimedia involves more senses and consequently leads to a more comprehensive form of learning. It can also be tailored to suit individual needs of. It can, therefore, be considered as a great tool for the solving the problems of mentally retarded students [2]. Since they encounter more problems in acquiring life skills and require more innovative forms of approach to learning, such a research will facilitate the training of mentally retarded students, programmed for enhanced knowledge retention.

Multimedia messages are designed considering how the human brain functions as opposed to other forms of media that are not planned accordingly. They are likely to lead to more effective and meaningful learning. In the cognitive theory of multimedia learning, it is assumed, firstly, that the human information processing system has two separate channels for processing: visual and auditory. Second, each channel has a limited capacity for processing. Finally, active learning requires the implementation of a series of steps in relation to cognitive processing during learning. Image processing occurs on the visual channel and processing spoken words like the voice of the announcer in a multimedia program occurs on the auditory channel. With regard to the printed word, processing initially occurs on the visual channel and then goes onto the auditory channel [4].
Zavaraki Zareie and Gharibi (2012) conducted a study titled "the impact of multimedia on learning and retention of math concepts to fourth grade educable mentally retarded students", using a quasi-experimental method. The results of this study showed superior learning and retention of knowledge by students received training through multimedia content in comparison with traditional training.

Weiner and Ingersoll (2010) carried out a study entitled "The impact of the use of computer technology to teach social skills to people with intellectual disability". They demonstrated in this study that the use of computer technology, such as interactive computer programs (multimedia) and virtual environments, can improve and develop social skills and effective communication of mentally retarded students.

\section{Methods}

The present study employed a pretest and posttest, with a control group, research design for the collection of data, making it a quasi-experimental research.

\section{Statistical population, sample size and sampling} methods

The statistical population included all educable, mentally retarded students in grades two and three of elementary schools in Qasr-e Shirin in the academic year 2014-2015. Twelve students were selected through accessible sampling method and were randomly assigned into control and experimental groups.

\section{Tool}

To collect data in this study, part of the questionnaire was developed by the country's Department of Exceptional Education to evaluate the self-help course for skills' training of mentally retarded students. Given that the subjects in this study were in the second and third grades of elementary school and belonged to the age group of 10-14 years, 38 items were framed for the questionnaire, and for the selection and performance

Table 1. Correspondence questionnaire with variables.

\begin{tabular}{cc}
\hline Category & Questions \\
\hline Development of personal skills (eating and drinking) & Question 1 to question 8 \\
Development of personal skills (dressing and undressing) & Question 9 to question 25 \\
Development of personal skills (personal hygiene) & Question 26 to question 38 \\
\hline
\end{tabular}

Iranian Rehabilitation Journal 
Table 2. Multimedia training program.

\begin{tabular}{|c|c|}
\hline Session & Objective \\
\hline First session & $\begin{array}{c}\text { Provide explanations with regard to the application of multimedia, and extend familiarity with computer system } \\
\text { and required computer terminology }\end{array}$ \\
\hline $\begin{array}{l}\text { Second ses- } \\
\text { sion }\end{array}$ & Teach how to cut pieces of fruit and peel their skin using multimedia elements \\
\hline Third session & Teach how to use the spoon and fork also utilizing multimedia elements \\
\hline Fourth session & Teach how to put on and open shoes using multimedia elements \\
\hline Fifth session & Teach how to bring out and wear jackets and gloves using multimedia elements \\
\hline Sixth session & Teach how to use open and close buttons as well as how to open and close zippers using multimedia \\
\hline $\begin{array}{l}\text { Seventh ses- } \\
\text { sion }\end{array}$ & Teach how to wash hands and face and brush using multimedia elements \\
\hline Eighth session & Teach how to wash clothes, dishes \\
\hline
\end{tabular}

levels of each question, the zero individually, half and one were considered (Table 1).

The items of the questionnaire were selected through election. Their validity and reliability were assessed, in the first phase, with the help of a detailed and comprehensive study of the variables. The proportion of questions with respect to each variable was examined in the second phase by way of comments from professors and experts in the field of exceptional children education. and their comments on editing and proofing test was applied common points in the third the test was distributed among number of exceptional teachers and they were asked to comment. To further assess the reliability, eight educable, mentally retarded students in the second and third grades of elementary school completed the questionnaire. After collecting and extracting results, the reliability coefficient obtained from Cronbach's alpha was 0.73 for the pretest and 0.82 for the posttest. These numbers indicated that this questionnaire had appropriate reliability and accuracy.

\section{Implementation method}

Because of the lack of multimedia education to provide training for the development of self-help and life skills among mentally retarded children, the researcher decided to design the same for the study group. To do so, he took into account various factors: the characteristics of the children, the use of audiovisual media, especially film and animation that attracts their attention and Mayer's cognitive theory of multimedia learning. The researcher also conducted surveys and consulted teachers of mentally retarded, who learn at a slow pace, students and their parents. Control group students were trained with the help of the traditional methods (with- out use of multimedia). Multimedia education used in the study was edited to match the format of the Persian content software and the training program was spread across eight sessions of 30 minutes each. The program was used to train the experimental group at the Bahar exceptional center of Qasr-e Shirin, as shown in Table 2.

\section{Data analysis method}

In the present study, two methods were used to analyze data. A: Descriptive statistics including tables, and mean and standard deviation by division of pretest and posttest scores of control and experimental group and the whole sample. B: Inferential statistics to compare the experimental and control groups in terms of mean score on the scales. Covariance analysis was used after reviewing its assumptions.

\section{Results}

In Table 3, mean scores in the pretest and posttest are presented. The mean score of self-help and life skills for the experimental group in the pretest was 11 and its value reached 21.16 at the posttest stage. The total score with regard to the said skills for the control group in the pretest was 10.50; in the posttest its value was 13.7.

Before conducting covariance analysis, it is necessary that its assumptions are met. It should be noted that one of the assumptions of the covariance test is the equality of variances of all dimensions of self-help and life skills. Table 4 shows the significance level of all dimensions is more than 0.05 . This indicates that the equality of variances default is confirmed in both the experimental and control groups. 
Table 3. Mean and standard deviation of self-help and life skills of the research groups in the pretest and post-test.

\begin{tabular}{|c|c|c|c|c|c|}
\hline \multirow{2}{*}{ Self-Help and Life Skills, and Its Dimensions } & \multirow[t]{2}{*}{ Test } & \multicolumn{2}{|c|}{ Experimental Group } & \multicolumn{2}{|c|}{ Control Group } \\
\hline & & Mean & $\begin{array}{l}\text { Standard } \\
\text { Deviation }\end{array}$ & Mean & $\begin{array}{l}\text { Standard } \\
\text { Deviation }\end{array}$ \\
\hline \multirow{2}{*}{ Total scores of self-help and life skills } & Pre-test & 11 & 18.18 & 10.50 & 4.15 \\
\hline & Post-test & 21.16 & 9.15 & 13.07 & 5.08 \\
\hline \multirow{2}{*}{ Skill required to eat and drink } & Pre-test & 2.52 & 2.01 & 2.58 & 1.59 \\
\hline & Post-test & 4.66 & 1.53 & 3.54 & 2.06 \\
\hline \multirow{2}{*}{ Skill required to put on clothes and undress } & Pre-test & 4.58 & 3.06 & 3.41 & 1.85 \\
\hline & Post-test & 9.91 & 3.66 & 3.51 & 1.87 \\
\hline \multirow{2}{*}{ Health skills } & Pre-test & 3.83 & 3.37 & 4.05 & 1 \\
\hline & Post-test & 7.08 & 3.76 & 6.02 & 2.36 \\
\hline
\end{tabular}

Iranian Rehabilitation Journa

Table 4. The results of the Levene test for the equality of variances default in the two groups.

\begin{tabular}{|c|c|c|c|c|}
\hline Scales & Test F & $\begin{array}{l}\text { First Degree of } \\
\text { Freedom }\end{array}$ & $\begin{array}{l}\text { Second Degree of } \\
\text { Freedom }\end{array}$ & Significance Level \\
\hline \multirow[b]{2}{*}{ Self-help and life skills, and its dimension } & 4.09 & 1 & 10 & 0.07 \\
\hline & 5.87 & 1 & 10 & 0.13 \\
\hline \multirow{2}{*}{ Total score of self-help and life skills } & 4.89 & 1 & 10 & 0.10 \\
\hline & 3.22 & 1 & 10 & 0.34 \\
\hline
\end{tabular}

Table 5 provides the adjusted means of the dependent variable for each group. Adjusted means ensure that the effect of change is statistically removed. As can be seen in the table, mean total scores of self-help and life skills in the ex- perimental group and the control group are 12.80 and 20.90 respectively. Other results can also be viewed in the table.

The main hypothesis of this research is that multimedia education affects the development of self-help and life

Table 5. Adjusted mean scores.

\begin{tabular}{cccc}
\hline Subscales & Groups & Mean & Error of Standard Deviation \\
\hline Total mean scores of self-help and life skills & Experimental & 20.90 & 0.869 \\
Skills required to eat and drink & Control & 12.80 & 0.869 \\
Skills required to put on clothes and undress & Experimental & 4.66 & 0.366 \\
& Control & 3.54 & 0.366 \\
Health skills & Experimental & 9.28 & 0.456 \\
& Control & 3.51 & 0.461 \\
\hline
\end{tabular}


Table 6. Covariance analysis of posttest scores of the experimental and control groups, with regard to self-help and life skills.

\begin{tabular}{|c|c|c|c|c|c|c|c|}
\hline Source & Subscales & Sum of Squares & df & $\begin{array}{l}\text { Mean of } \\
\text { Squares }\end{array}$ & $\mathbf{F}$ & Sig. & $\begin{array}{c}\text { Etha } \\
\text { Amount }\end{array}$ \\
\hline Pretest & & 464.54 & 1 & 464.54 & 102.50 & 0.001 & 0.919 \\
\hline Group membership & Life skills & 308.01 & 1 & 308.01 & 67.96 & 0.001 & 0.88 \\
\hline
\end{tabular}

skills of among educable, mentally retarded students belonging to the second and third grades. Covariance analysis was used to examine the hypothesis in Table 6 below.

Based on the results of Table 6, and after adjusting pretest scores and considering the significant difference between adjusted means (Table 5) of the groups, it can be concluded that the multimedia education has been able to increase the score of self-help and life skills at the posttest stage totally. Multimedia education, in fact, had a significant effect on enhancing these skills. The results showed that the group level (0.001), there is a significant difference and this means that it has a multimedia learning these skills at post-test mean score increase.

\section{Discussion}

The main hypothesis is that multimedia education affects the development of self-help and life skills of among educable, mentally retarded students belonging to the second and third grades. The results of Table 5 showed that with respect to total self-help and life skills, the adjusted mean score of the control group had no significant difference between the adjusted mean score of the experimental group at the pretest stage. But after the implementation of multimedia education program on the experimental group, at its adjusted mean scores had a significant advantage over the adjusted mean scores of the control group.

The results showed that training multimedia education at post-test has increased the amount of total score of life skills based on self-help and between the groups in the level (0.001) there is a significant difference it means that Multimedia Educational had a significant effect on life skills based on self-help of exceptional students, so the hypothesis is confirmed. The overall result of this study is consistent with the results of Zaraii Zavaraki [1], and Wainer and Ingersoll [10] study.

In these studies, learning increased for students with intellectual disability in various fields with the help of computers and multimedia compared with traditional methods. This was due to the fact that several senses of the concerned students were engaged at the same time in the learning process. A structured, coherent and predictable environment was created that enabled them to perform activities repeatedly, using their special skills.

\section{Conclusion}

In conclusion, it can be stated that the result of the research, which is supported by previous research findings, can be considered to be a new horizon in the process of training. It highlights multimedia as an active method of education that uses new procedures such as employing several senses in the process of learning, engaging the learner, making the learning environment flexible, and paying attention to the needs of children with special needs and students with mental retardation. Some researchers [8] stated that exceptional people tend to visual stimulus for learning relatively and process visual stimulus better than other stimuli [6].

\section{Limitations of the study}

It is time consuming to design multimedia software, keeping in mind the principles of multimedia design and features of mentally retarded children. The number of students were limited, with the subjects representative of just two grades. The area of research was limited to the Center of Special Education in Qasr-e Shirin. Therefore, caution should be exercised while generalizing results. In this study, a follow up period was not observed. Therefore, the results may not be stable.

\section{Practical suggestions}

Keeping in mind the findings obtained from the research, the following suggestions are offered: It is recommended that the designed software be reproduced and provided to instructors who train exceptional students. Multimedia education should be offered alongside traditional methods. The latter is considered by instructors of exceptional students currently. Because children with intellectual disabilities spend most of their time at home and with their parents, it is recommended that parents be familiarized with computers and multimedia education. 


\section{Research suggestions}

Production of multimedia for educable, mentally retarded children, considering the characteristics of other courses, educational levels and its effects on other variables. Given that in this study for the first in the country the Persian content production software as "content of knowledge" which has been approved by the Ministry of Education and the Supreme Council of Informatics was used to design and multimedia production therefore, it is suggested that, if possible, other research be done using this software.

It is recommended that this study be conducted again, with a follow up period being observed. It is also recommended that the study be carried out on a larger sample, representative of different areas of the city, so as to be in a position to generalize results.

\section{Acknowledgments}

The present study is extracted from the MA thesis of the third author, Department of Educational Management, Kermanshah Branch, Islamic Azad University.

\section{Conflict of Interest}

The authors declared no conflict of Interests.

\section{References}

[1] Zaraii Zavaraki I, Gharibi F. [The Impact of instructional multimedia on learning and retention of mathematics of fourth grade educable mentally retarded girl students of elementary schools in Arak City (Persian)]. Psychology of Exceptional Individuals. 2011; 2(5):1-19.

[2] Shir Mohammadi MM, Chahardoli M. [An Introduction to multimedia environments (Persian)]. Hamadan: Daneshjoo Publications; 2002.

[3] Ghanbari BA, Saadat Baghsyah M. [Effectiveness of rithmic movements on social communication of MR child of Sangan and Khavaf city (Persian)]. Studies in Education and Psychology. 2010; 11(1):171-88

[4] Meyer RE, Anderson RB. Animations need narration: An examperimental test of a dual-codinghypothsis. Journal of Educational psychology. 2001; 83(4):484-490. doi: 10.1037//00220663.83.4.484

[5] Milanifar B. [Psychology of exceptional children (Persian)]. Tehran: Ghoomes Publication; 2010.

[6] Norouzi D, Bayani A. [Efficacy of multimedia teaching on learning and retention of arithmetic in autistic students (Persian)]. Psychology of Exceptional Individuals. 2011; 1(4):23-
[7] Ayer K, Longone J. Intervention and instruction with video for studentswith autism: A review of children of the literature. Education \& Training in Developmental Disabilities. 2005; 40(60):183-96.

[8] McCoy K, Hermansen E. Video modeling for individuals with autism: A review of model types and effects. Education \& Treatment of Children. 2007; 30(4):183-213. doi: 10.1353/ etc. 2007.0029

[9] Ray CE, Elliott SN, Deci EL, Ryan RM. Self- determination theory: A macro theory of human motivation, development and health. Canadian Psychology. 2006; 49(3):182-185. doi: $10.1037 / \mathrm{a} 0012801$

[10] Wainer AL, Ingersoll BR. The use of innovative computer technology for teaching social communication to individuals with autism spectrum disorders. Research in Autism Spectrum Disorders. 2011; 5(1):96-107. doi: 10.1016/j. rasd.2010.08.002 